\title{
Family Eating and Physical Activity Practices Among African American, Filipino American, and Hispanic American Families: Implications for Developing Obesity Prevention Programs \\ Asian/Pacific Island Nursing Journal \\ Volume 1(3): 127-136 \\ (C)Author(s) 2016 \\ http://digitalscholarship.unlv.edu/apin/
}

\author{
Luz Sobong Porter ${ }^{\mathrm{a}}$
}

\begin{abstract}
Overweight and obesity among children and adults is well-documented as an escalating problem. The purpose of this study is to determine the blood pressure, self-esteem, and eating and physical activity practices among African Americans, Filipino Americans, and Hispanic Americans; and project implications for development of childhood obesity prevention programs. This descriptive study was conducted in a convenience sample of 110 mothers recruited in health clinics and community centers located in Southeast Florida: 19\% African Americans, 26\% Filipino Americans, and 55\% Hispanic Americans. The data, collected via self-administered questionnaires and a guided interview (Family Eating and Activity Habits Questionnaire, Rosenberg's Self-Esteem Scale, Background Information Questionnaire), were analyzed via descriptive and inferential statistics with findings significant at $p<.05$. Results revealed differences and similarities in eating and activity practices between Filipinos and Blacks or Hispanics. Blood pressure and self-esteem did not differ by ethnicity; however, overweight mothers tended to have overweight children. The results point clearly to the importance of the mothers' role modeling in eating and physical activity practices of families, reflecting the influence of mothers' behaviors in children's healthy behaviors, albeit family health. Given that mothers own physical exercise and eating habits could influence their children's physical activity levels and food choices, a parental advice strategy could be disseminated directly to parents by health professionals. Study findings may raise public awareness of the increasing prevalence and consequences of overweight and obesity in children and adolescents, particularly among vulnerable ethnic groups. The findings provide a database for nurse practitioners and other health service providers for the development of culturally sensitive focused public health education programs to prevent or control obesity.
\end{abstract}

Keywords: African Americans; Filipino Americans, Hispanic Americans, family eating habits, physical activity practices

The Centers for Disease Control and Prevention reported that $65 \%$ of the U.S. population is overweight or obese (Flegal, Carroll, Kit, \& Ogden, 2012). Since 1980, the prevalence of overweight children and overweight adolescents has more than doubled and more than tripled, respectively, and about $60 \%$ of overweight children have at least one risk factor for cardiovascular disease, such as high blood pressure or high cholesterol. Children who are overweight are poised to become overweight or obese adults with the attendant high risk of co-morbidities as well as the psychosocial consequences of systematic discrimination that can seriously affect the healthy development of self-esteem and body image (Fitzgerald \& Mousouli, 2008). The two-fold purpose of this study was to determine differences in blood pressure, dietary

${ }^{a}$ Florida International University, USA

Corresponding Author:

Luz Sobong Porter, PhD, ARNP, FNP, FAANP, FAAN

Professor Emerita, College of Nursing and Health Sciences

Florida International University

Email: luzporter@comcast.net

c) (i) $\Theta$ Creative Commons CC-BY-NC-ND: This article is distributed under the terms of the Creative Commons Attribution 4.0 LiNo cense (http://creativecommons.org/licenses/by/4.0/) which allows others to download your works and share them with others as long as they credit you, but they can't change them in any way or use them commercially. 
patterns, and physical activity practices among African Americans, Filipino Americans, and Hispanic Americans in South Florida; and to determine differences in dietary patterns and physical activity practices among fathers, mothers, and children. It was projected that the research findings would contribute to a systematic database upon which to design communitybased health education or intervention programs that are sensitive to the cultural uniqueness of the target population.

\section{Background}

Studies have shown that in the past 40 years, the body mass index (BMI) of children and adolescents has consistently risen to higher levels, with this increase being attributed to the influence of changing social environments (Davies \& Fitzgerald, 2008; LobCorzilius, 2007). In 2006, the Centers for Disease Control and Prevention reported that $5 \%$ of the U.S. population is overweight or obese and obesity affects 60 million people, 9 million being seriously obese and 127 million being overweight (Dhoble, Patel, \& Odoms-Young, 2007). Obesity and overweight are a result of an imbalance between food consumption and physical activity; however, obesity is a complex issue related to lifestyle, environment, and genes. Obesity is an excess of adipose tissue (body fat) and is manifested by a BMI of $30 \mathrm{~kg} / \mathrm{m}^{2}$ or higher for adults, and a BMI at or above the $95^{\text {th }}$ percent for children and adolescents (Dunphy, Brown-Winland, Porter, \& Thomas, 2015). In the United States, $30 \%$ of Americans are overweight with a BMI of 25 and $29 \mathrm{Kg} / \mathrm{m}^{2}$. The increase in obesity has been linked to many underlying factors, such as eating out more often; increasing portion sizes; increased consumption of sugar-sweetened drinks; increased television viewing, computer, electronic gaming time; and minimal or no outdoor exercise. The influence of television viewing has an effect on the amount of physical activity that children participate in, the amount of food they intake, and may have an effect on their metabolic rates. Television viewing and computer or video games encourage sedentary activities and are conducive to developing overweight or obesity (Butte et al., 2007).

A study by Pan et al. (2009) found that $21 \%$ of Hispanics were more obese than non-Hispanic Whites, and $51 \%$ of non-Hispanic Blacks were more obese that non-Hispanic Whites. Hispanic children had significantly higher levels of obesity than White, Black, and Asian ethnic groups (Thorpe, Florence, Howard, \& Joski, 2004). Low-income women and their children are at higher risk for overweight and obesity than higher income groups. Food consumed by children and adolescents has been implicated as a factor in obesity. Food intake and physical activity are lifestyle behaviors learned early in childhood and are often indicative of lifestyle choices pursued in adulthood (Huang, Ball, \& Franks, 2007).

Wang and Beydoun (2007) found large racial and ethnic disparities in overweight among children and adolescents in the United States. They found that non-Hispanic Black and Mexican American youth had disproportionately higher rates of overweight compared to non-Hispanic White youth (non-Hispanic Blacks are Americans who are defined by the Census Bureau as coming from Africa; whereas Mexican Americans refer to Americans of full or partial Mexican descent). It was predicted that by 2015 , overweight in these populations would reach $31 \%$ and $33 \%$, respectively. A similar pattern in overweight was observed for male and female adolescents, aged 12-19 years, $50 \%$ of which were found to be at risk for overweight or already overweight (Wang \& Beydoun, 2007). Another study found a significant difference in overweight among races, with Hispanic students having the highest prevalence, followed by African American students. White students were least likely to be overweight (Vieweg, Johnston, Lanier, Fernandez, \& Pandurangi, 2007).

Home, school, and community environments are the most influential on eating and physical activity behaviors of children and adolescents (Booth, Wilkenfeld, Pagnini, Booth, \& King, 2008; Hudson, 2008). Investigators assert that the home environment is the most influential setting for shaping children's eating and physical activity behaviors (Campbell et al., 2007; Sealy, 2010). Studies have shown that physical fitness participation begins to decline during adolescence, especially among girls. There are several barriers that contribute to the drop in activity among middle-school girls. One study (Ammouri, Kaur, Neuberger, Gajewski, \& Choi, 2007) identified competition as a deterrent factor. Adolescent males are more likely to engage in team sports because they enjoy competition. Girls prefer social activities because peer relationships are important during this developmental period. It was concluded that positive relationships with a parent made it easier for female adolescents to be physically active due to positive role model behavior, increased verbal encouragement, and provision of transportation. Also, less than $30 \%$ of school-aged children participate in daily structured physical education activities aimed at fitness and prevention of overweight (Schneider et al., 2007).

Among African American children, studies have shown that females were more likely to be obese than males (Flegal et al., 2012; Hughes et al., 2006). However, most African American parents did not seem to recognize the problem of overweight in their children (Young-Hyman, Schlundt, Herman-Wenderoth, \& Bozylinski, 2003). Only $30 \%$ of the parents 
admitted then that their child was overweight despite the fact that $85 \%$ of the children were overweight. Hispanic children had significantly higher levels $(31 \%)$ of obesity compared to White, Black, and Asian ethnic groups (Thorpe et al., 2004). In the past 30 years, the overweight prevalence rates have doubled in this age group and among African American and Hispanic children, the rates are even higher (Schmitz et al., 2002).

Urbanization and economic development are major driving transformations in dietary habits and physical activity that can be linked to the rapid increase in obesity in developing countries (Colchero \& Bishai, 2008). The increasing prevalence of obesity in several Asian countries has been attributed to rapid modernization, lifestyle changes, western culture influences, and decreased physical activity. These social and economic changes increase the consumption of processed foods, animal fats, simple sugars, and an overall increase in total energy intake reflect the nutrition transition. Kelles and Adair (2009) indicated that there may be heterogeneity in dietary responses to social and economic changes within strata of socioeconomic status. In most high-income and middle-income countries, income is negatively associated with obesity, the higher rates of obesity being among the poorest people (Colchero \& Bishai, 2008). However, obesity is less prevalent in rural areas where food supply is limited and work related activities are more physically demanding (Colchero \& Bishai, 2008; Dammann \& Smith, 2009). Intuitive eating is food consumption that is primarily motivated by the physical satisfaction of hunger. Thus, a dietary change in developing countries appears to be influenced by rapid modernization. However, there is a lack of research data on obesity among Filipino Americans which makes it difficult to design and implement effective interventions (Parizkova, Chun, Chia, \& Yang, 2007).

Although Filipinos are the second largest Asian subgroup in the United States, few studies have examined health and health care disparities in Filipino children. However, the increasing prevalence of obesity during the last few decades observed in the Philippines has been attributed to rapid modernization, lifestyle changes, decreased physical activity, and western culture influences. Kelles \& Adair (2009) claimed that there is supporting evidence that the nutrition transition has affected the Filipino population. Acculturation was associated with a higher frequency of fast food consumption and a decrease in frequency in physical activity (Unger et al., 2004). Homegrown traditional foods slowly become replaced with more energy dense animal products, processed foods, and store-bought convenience foods. Mothers and their children are likely to consume more calories relative to basal metabolic needs as well as higher percentages of calories from fat, reflecting rapid urbanization and increasing socioeconomic status (Hawks et al., 2004).

In the Behavioral Risk Factor Surveillance System Survey data from Hawai'i on physical activity, over $45 \%$ of Filipinos reported that they were inactive or insufficiently active, the highest percentage for any ethnic group surveyed (Hawai'i Department of Health, 2011). Whereas half of Filipino respondents reported getting recommended levels of physical activity, the second generation Filipinos reported lower levels of non-leisure time physical activity compared with first generation Filipinos. Filipino children are less likely to be physically active compared with their white counterparts (Afable-Munsuz, Ponce, Rodriguez, \& Perez-Stable, 2010; Javier, Huffman, \& Mendoza, 2007; Kelles \&Adair, 2009).

Filipinos have reported diets that were high in animal fat and excess calories compared with other groups (Kim, Park, Grandinetti, Holck, \& Waslien, 2008). Younger Filipinos are more likely to consume diets that are high in fat, red meat, and dairy products compared with older Filipinos (Brooks, Leake, Parsons, \& Pham, 2012). There may be heterogeneity in dietary responses to social and economic changes within strata of socioeconomic status (Kelles \& Adair, 2009). In most high-income and middle-income countries, income is negatively associated with obesity, the higher rates of obesity being among the poorest people. However, obesity is less prevalent in rural areas where food supply is limited and work related activities are more physically demanding (Colchero \& Bishai, 2008). Thus, a dietary change in developing countries appears to be influenced by rapid modernization.

\section{Method}

\section{Research Design}

This comparative-descriptive study was conducted in health clinics, churches, community centers, and homes. Subject recruitment and data collection were done after the research protocol was approved by the University's Institutional Review Board, the directors of the community health agencies, and the respective parents. Poster board and study announcements were posted in the reception areas and consent from each parent was secured prior to data collection. Each consented parent signed an informed consent and each child signed an assent form. The data were collected from the mother via structured interview or self-administered questionnaires, which took 35-45 min for each respondent, the Family Eating and Activity Habits Questionnaire developed by Golan and Weizman (1998) and the Basic Background 
Information Questionnaire. The Family Eating and Activity Habits Questionnaire has a Cronbach alpha of .83 (Golan \& Weizman, 1998) and was used to collect the data on the sample's dietary and activity practices. The Background Information Questionnaire was used to gather information on age, gender, weight, race/ethnicity, family composition, and grade level of parents and children, as well as mothers' blood pressure.

\section{Data Analysis}

Data analysis included descriptive analysis to characterize the sample and inferential statistics: ANOVA to examine independent and interactive effects; a paired $t$-test to compare the practices between/among mothers, fathers, and children; and Tukey's Post Hoc test to determine which between ethnic groups (Filipino vs. Black vs. Hispanic) had significantly higher or lower scores. Specifically, this study was focused on determining whether Filipinos, Blacks, and Hispanics differ in family eating habits (FEH) and activity practices (AP), and whether there is a difference between mothers, fathers, and children in FEH and AP.

\section{Results}

\section{Sample Profile}

The sample was composed of 21 Filipinos (12 females, 7.60\%; 9 males, 5.70\%), 32 Blacks (19 females, $9.90 \%$; 13 males, $7.60 \%$ ), and 105 Hispanics (81 females, 51.60\%; 24 males, $15.30 \%$ ), reflecting the geographic distribution of the population in southeast Florida. There were 112 female participants $(71.30 \%)$ in the study, and the majority were born in the United States $(n=93,58.90 \%)$. However, the majority of the Filipino and Hispanic mothers were born in their native land. Most of the participants have 1-2 siblings $(n=71,45.50 \%)$ followed by those with $3-4$ siblings $(n=49,31.40 \%)$. For Filipinos, $10(6.40 \%)$ had 1-2 siblings and only two (1.30\%) had five or more siblings. For Blacks, 19 (12.20\%) had 1-2 siblings and seven (\%) had 3-4 siblings; no one reported having more than five siblings. For Hispanics, 42 (26.90\%) had 1-2 siblings while $15(9.60 \%)$ have more than five siblings. Most of the participants were in the 11 th-12th grade $(n=46,29.30 \%)$ followed by those in the 6 th- 8 th grade $(n=38,24.20 \%)$. The majority of the Filipino participants were in the 9 th-10th grade $(n$ $=6,3.80 \%$ ), majority of the Black participants were in the 6th-8th grade $(n=13,8.30 \%)$, and majority of the Hispanic participants were in 11th-12th grade $(n=40$, $25.50 \%)$.
The majority of Black or Hispanic participants were living in a single-parent home (51\%). The majority of the sample was bilingual: English and Tagalog for Filipinos, English and Spanish for Hispanics, but for Blacks, Creole was predominantly spoken at home $(n=34,32 \%)$. Black mothers $(M=154.59, S D$ $=51.68)$ were heavier than Hispanics $(M=146.48, S D$ $=50.92)$, and Hispanics were heavier than Filipinos $(M=122.11, S D=51.73)$. The highest systolic blood pressure were among Hispanic mothers $(M=124.06$, $S D=22.71)$, followed by Filipino mothers $(M=$ $115.56, S D=29.21)$. However, the highest diastolic blood pressure were among Hispanic mothers $(M=$ $74.17, S D=11.75)$ followed by Black mothers $(M=$ $71.08, S D=9.68)$. In self-esteem, Black mothers had the highest standard error mean score $(M=36.45, S D$ = 3.80), and both Filipino and Hispanic mothers had approximately equivalent standard error mean scores. The three ethnic groups were similar in demographic characteristics, except for age: the Hispanics having a mean age of 22.56 years, versus the mean ages of 13.53 and 12.67 for Filipino and Black mothers, respectively. This age discrepancy may be due to Filipino and Black mothers not recording their ages, but instead recording their child/children's age.

\section{Family Eating and Physical Activity Practices}

Table 1 presents the ANOVA for significant aspects of family eating habits and activity practices according to ethnic groups. Blacks, Filipinos, and Hispanics differed significantly in several aspects of family eating and activity practices. Overall, the fathers differed significantly in TV and computer usage. As shown in Table 1, the three ethnic groups also differed with regard to eating snacks and sweets; however, Hispanic mothers added more snacks and sweets during weekends than Blacks or Filipinos. The most common types of snacks that participants kept in their home included pretzels, nuts, and cookies. Snacks and sweets were kept in a visible place by $53 \%$ of participants, while $47 \%$ of participants kept snacks and sweets in a known but not visible place. When asked about eating pace, $67 \%$ of mothers considered their eating pace to be average, $60 \%$ of fathers considered their pace as fast, and $60 \%$ of children were considered to be average. There was a significant difference among the three ethnic groups with respect to the eating pace of the child, the eating pace of the mother, the child eating when hungry, and mothers' taking a second helping. The majority of mothers (40\%) and fathers (53\%) never took a second helping during meals, while $47 \%$ of children took a second helping. Dinner (53\%) was the meal most frequently eaten together as a family. 
Porter: Family Eating and Physical Activity

Table 1. ANOVA for Family Eating Habits and Physical Activity Practices according to Ethnicity

\begin{tabular}{|c|c|c|c|c|c|c|}
\hline Variables & Groups & $\begin{array}{l}\text { Sum of } \\
\text { Squares }\end{array}$ & $d f$ & Mean Square & $F$ & $p$ \\
\hline TV/Computer Usage & Between Groups & 7588.487 & 2 & 3794.243 & 3.836 & $.025 *$ \\
\hline \multirow[t]{2}{*}{ Mother } & Within Groups & 89999.864 & 91 & 989.009 & & \\
\hline & Total & 97588.351 & 93 & & & \\
\hline TV/Computer Usage & Between Groups & 12899.983 & 2 & 6449.991 & 5.507 & $.006 *$ \\
\hline \multirow[t]{2}{*}{ Father } & Within Groups & 81987.058 & 70 & 1171.244 & & \\
\hline & Total & 94887.041 & 72 & & & \\
\hline TV/Computer Usage & Between Groups & 511.859 & 2 & 255.929 & 3.180 & $.046 *$ \\
\hline \multirow[t]{2}{*}{ Child } & Within Groups & 7404.246 & 92 & 80.481 & & \\
\hline & Total & 7916.105 & 94 & & & \\
\hline Physical Activities & Between Groups & 7490.120 & 2 & 3745.060 & 4.816 & $.013 *$ \\
\hline \multirow[t]{2}{*}{ Father } & Within Groups & 36547.800 & 47 & 777.613 & & \\
\hline & Total & 44037.920 & 49 & & & \\
\hline \multirow[t]{3}{*}{ Bored Child } & Between Groups & 10.748 & 2 & 5.374 & 3.860 & $.024 *$ \\
\hline & Within Groups & 130.881 & 94 & 1.392 & & \\
\hline & Total & 141.629 & 96 & & & \\
\hline \multirow[t]{3}{*}{ Snacks } & Between Groups & 90.313 & 2 & 45.156 & 25.980 & $.000 * *$ \\
\hline & Within Groups & 161.646 & 93 & 1.738 & & \\
\hline & Total & 251.958 & 95 & & & \\
\hline \multirow[t]{3}{*}{ Sweets } & Between Groups & 19.000 & 2 & 9.500 & 7.244 & $.001 * *$ \\
\hline & Within Groups & 121.958 & 93 & 1.311 & & \\
\hline & Total & 140.958 & 95 & & & \\
\hline \multirow[t]{3}{*}{ Add on Weekends } & Between Groups & 6.214 & 2 & 3.107 & 6.677 & $.002 *$ \\
\hline & Within Groups & 43.275 & 93 & .465 & & \\
\hline & Total & 49.490 & 95 & & & \\
\hline Child Eats Snacks & Between Groups & 12.479 & 2 & 6.239 & 3.160 & $.047 *$ \\
\hline \multirow[t]{2}{*}{ w/o Permission } & Within Groups & 185.583 & 94 & 1.974 & & \\
\hline & Total & 198.062 & 96 & & & \\
\hline \multirow[t]{3}{*}{ Child is Hungry } & Between Groups & 24.614 & 2 & 12.307 & 16.628 & $.000 * *$ \\
\hline & Within Groups & 69.571 & 94 & .740 & & \\
\hline & Total & 94.186 & 96 & & & \\
\hline \multirow[t]{3}{*}{ When Child Eats } & Between Groups & 16.679 & 2 & 8.339 & 28.782 & $.000^{* *}$ \\
\hline & Within Groups & 26.946 & 93 & .290 & & \\
\hline & Total & 43.625 & 95 & & & \\
\hline \multirow[t]{3}{*}{ Mother's Behaviors } & Between Groups & 375.981 & 2 & 187.990 & 3.889 & $.024 *$ \\
\hline & Within Groups & 4737.227 & 98 & 48.339 & & \\
\hline & Total & 5113.208 & 100 & & & \\
\hline \multirow[t]{3}{*}{ Child's Behaviors } & Between Groups & 339.846 & 2 & 169.923 & 3.284 & $.042 *$ \\
\hline & Within Groups & 4967.265 & 96 & 51.742 & & \\
\hline & Total & 5307.111 & 98 & & & \\
\hline \multirow[t]{3}{*}{ Eating Pace Mother } & Between Groups & 17.565 & 2 & 8.783 & 25.055 & $.000 * *$ \\
\hline & Within Groups & 32.950 & 94 & .351 & & \\
\hline & Total & 50.515 & 96 & & & \\
\hline \multirow[t]{3}{*}{ Eating Pace Child } & Between Groups & 20.554 & 2 & 10.277 & 20.638 & $.000 * *$ \\
\hline & Within Groups & 46.807 & 94 & .498 & & \\
\hline & Total & 67.361 & 96 & & & \\
\hline Second Helping & Between Groups & 11.169 & 2 & 5.585 & 3.684 & $.029 *$ \\
\hline \multirow[t]{2}{*}{ Mother } & Within Groups & 142.501 & 94 & 1.516 & & \\
\hline & Total & 153.670 & 96 & & & \\
\hline
\end{tabular}

Note. Includes the items from the Family Eating and Activity Practices tool that were found to be significant. *p $<.05 ; * * p<.01$

In order to determine the significantly higher and lower scores between the ethnic groups, Tukey's Post Hoc test (Table 2) on the sub-items with significant differences was conducted. Blacks had a longer average time of TV and computer usage than Hispanics. For the TV and computer usage of fathers, Blacks also had a higher mean usage time than
Filipinos, but Filipino fathers devoted more time to these activities than Hispanics. Black mothers and Black children had higher mean time spent for TV/computer games than Hispanics or Filipinos, $(p=$ .025 and $p=.046$, respectively). The majority of the mothers $(53 \%)$ ate while watching television, reading, or working, while $40 \%$ of the fathers and $27 \%$ of the 
Asian/Pacific Island Nursing Journal, Vol. 1, Iss. 3 [2016], Art. 8

Table 2. Tukey's Post Hoc for Family Eating Habits and Activity Practices according to Ethnicity

\begin{tabular}{|c|c|c|c|c|c|c|c|}
\hline \multirow[b]{3}{*}{ Dependent Variable } & \multirow{3}{*}{$\begin{array}{l}\text { (I) } \\
\text { Ethnicity } \\
\text { Group }\end{array}$} & \multirow{3}{*}{$\begin{array}{l}(\mathrm{J}) \\
\text { Ethnicity } \\
\text { Group }\end{array}$} & \multirow{3}{*}{$\begin{array}{c}\text { Mean } \\
\text { Difference } \\
(\mathrm{I}-\mathrm{J})\end{array}$} & \multirow[b]{3}{*}{$S E$} & \multirow[b]{3}{*}{$p$} & \multicolumn{2}{|c|}{$95 \% \mathrm{CI}$} \\
\hline & & & & & & Lower & Upper \\
\hline & & & & & & Bound & Bound \\
\hline TV/Computer Usage Mother & Black & Hispanic & 23.47684 & 8.475 & $.018 *$ & 3.283 & 43.671 \\
\hline \multirow[t]{2}{*}{ TV/Computer Usage Father } & Filipino & Black & -30.67424 & 12.461 & $.043 *$ & -60.513 & -.835 \\
\hline & Black & Hispanic & 38.88038 & 11.717 & $.004 * *$ & 10.822 & 66.939 \\
\hline TV/Computer Usage Child & Black & Hispanic & 5.81789 & 2.418 & $.047 *$ & .058 & 11.578 \\
\hline Physical Activities Father & Filipino & Hispanic & 26.53333 & 9.026 & $.014 *$ & 4.690 & 48.377 \\
\hline Bored Child & Filipino & Hispanic & -.76786 & .281 & $.020 *$ & -1.436 & -.100 \\
\hline \multirow[t]{2}{*}{ Snacks } & Filipino & Black & 1.88889 & .384 & $.000 * *$ & .975 & 2.803 \\
\hline & & Hispanic & 2.24306 & .317 & $.000 * *$ & 1.488 & 2.998 \\
\hline \multirow[t]{2}{*}{ Sweets } & Filipino & Black & .95767 & .333 & $.014 *$ & .164 & 1.751 \\
\hline & & Hispanic & 1.00231 & .275 & $.001 * *$ & .346 & 1.658 \\
\hline Add on Weekends & Black & Hispanic & -.64583 & .178 & $.001^{* *}$ & -1.071 & -.221 \\
\hline Child Eats Snacks w/o Permission & Filipino & Hispanic & .83333 & .334 & $.038 *$ & .038 & 1.629 \\
\hline \multirow[t]{2}{*}{ Child is Hungry } & Filipino & Black & -1.28571 & .248 & $.000 * *$ & -1.877 & -.694 \\
\hline & Black & Hispanic & 1.17857 & .225 & $.000 * *$ & .643 & 1.715 \\
\hline \multirow[t]{2}{*}{ When Child Eats } & Filipino & Black & .89286 & .155 & $.000 * *$ & .523 & 1.263 \\
\hline & Black & Hispanic & -1.05471 & .141 & $.000^{* *}$ & -1.391 & -.718 \\
\hline Mother's Behavior & Filipino & Hispanic & -4.04342 & 1.635 & $.040 *$ & -7.935 & -.152 \\
\hline Child's Behavior & Black & Hispanic & -4.48381 & 1.870 & $.048 *$ & -8.937 & -.031 \\
\hline \multirow[t]{2}{*}{ Eating Pace Mother } & Filipino & Black & .95000 & .173 & $.000 * *$ & .537 & 1.363 \\
\hline & Black & Hispanic & -1.09286 & .157 & $.000 * *$ & -1.467 & -.719 \\
\hline \multirow[t]{2}{*}{ Eating Pace Child } & Filipino & Black & .97857 & .207 & $.000^{* *}$ & .487 & 1.471 \\
\hline & Black & Hispanic & -1.19286 & .187 & $.000 * *$ & -1.639 & -.747 \\
\hline Second Helping Mother & Black & Hispanic & -.88673 & .327 & $.021 *$ & -1.665 & -.109 \\
\hline Afternoon/Snack & Filipino & Hispanic & -.69071 & .284 & $.045^{*}$ & -1.368 & -.014 \\
\hline
\end{tabular}

Note. Includes only the items that were found to be significant. ${ }^{*} p<.05 ; *^{*} p<.01$.

children ate while watching television, reading, or working. Although subjects watched a lot of television weekly, they also participated in physical activities. Mothers walked the most number of hours weekly for an average time of $1.2 \mathrm{hr}(S D=1.4)$ per week. Fathers did other activities for $1.1 \mathrm{hr}(S D=2.7)$ per week, while children did other activities for $3.8 \mathrm{hr}(S D=5.1)$ per week.

Filipino mothers' reported that their children spent an average of 2-40 hr per week in physical activities, commonly tennis and swimming. Black children ranged from 4-176 hr per week on physical activities, commonly running and sports. Overall, children were bored more easily than their mothers or fathers, and Hispanic children particularly were bored more easily than Filipino children when left alone. The findings demonstrated that Black children scored significantly higher than Hispanics having meals in the TV room, while Hispanic mothers scored significantly higher than Blacks.

Table 2 also shows that Filipinos ate more snacks and sweets than Hispanics or Blacks, but Hispanics added more of the snacks and sweets during weekends than Blacks. Also, Filipino mothers have more children that ate snacks without asking permission than Hispanic children. With respect to children eating when they were hungry, Blacks scored significantly higher than Filipinos and Hispanics; and for eating habits of children, Black children scored significantly lower than Filipinos or Hispanics. Black mothers scored lower than Hispanics and Filipinos for times when the mother eats with the child in the afternoon, or when the mother took a second helping during mealtimes.

On paired $t$-tests for activity practices (Table 3 ), it was found that mothers spent significantly more leisure time than their children; however, leisure time classes (including exercise classes) were attended more frequently by children, averaging 2-2.1 hr per week. Leisure time was not indicated for specific activities; it was spare time. Children frequently get bored when they were not kept busy, and when alone, children got bored more often than mothers did. Overall, mothers' eating in the TV room was highly associated with children eating in the TV room. Fourteen $(93 \%)$ children ate when they were hungry, $47 \%$ of the children ate only when the food was offered by the mother or father, and the majority of parents (40\%) suggested that the child would eat later if it was meal time and the child was not hungry. The majority of mothers $(47 \%)$ and fathers $(53 \%)$ would not eat if they were not hungry. 
Table 3. Paired Samples t-test Results for Family Eating Habit and Activity Practices

\begin{tabular}{|c|c|c|c|c|c|}
\hline & \multicolumn{2}{|c|}{ Paired Differences } & \multirow[b]{2}{*}{$t$} & \multirow[b]{2}{*}{$d f$} & \multirow[b]{2}{*}{$p$} \\
\hline & $M$ & $S D$ & & & \\
\hline TV/Computer Usage Mother - TV/Computer Usage Father & 1.662 & 6.883 & 2.035 & 70 & $.046^{*}$ \\
\hline TV/Computer Usage Mother - TV/Computer Usage Child & -.609 & 31.464 & -.186 & 91 & .853 \\
\hline TV/Computer Usage Father - TV/Computer Usage Child & -.169 & 35.960 & -.040 & 70 & .969 \\
\hline Activities Mother - Activities Father & -.913 & 9.390 & -.659 & 45 & .513 \\
\hline Activities Mother - Activities Child & .703 & 11.096 & .545 & 73 & .588 \\
\hline Activities Father - Activities Child & 1.900 & 16.529 & .813 & 49 & .420 \\
\hline Leisure Time Mother - Leisure Time Father & .013 & 2.665 & .042 & 77 & .966 \\
\hline Leisure Time Mother - Leisure Time Child & -1.063 & 4.373 & -2.370 & 94 & $.020 *$ \\
\hline Leisure Time Father - Leisure Time Child & -1.269 & 4.898 & -2.289 & 77 & $.025^{*}$ \\
\hline Bored Mother - Bored Father & .410 & .999 & 3.626 & 77 & $.001 * *$ \\
\hline Bored Mother - Bored Child & -.750 & 1.205 & -6.097 & 95 & $.000 * *$ \\
\hline Bored Father - Bored Child & -1.090 & 1.153 & -8.347 & 77 & $.000 * *$ \\
\hline Mother's Behavior - Father's Behavior & 1.316 & 5.886 & 1.949 & 75 & .055 \\
\hline Mother's Behavior - Child's Behavior & -.202 & 3.917 & -.513 & 98 & .609 \\
\hline Father's Behavior - Child's Behavior & -1.566 & 6.206 & -2.199 & 75 & $.031 *$ \\
\hline Eat in Room Mother - Eat in Room Father & -.075 & 2.775 & -.262 & 92 & .794 \\
\hline Eat in Room Mother - Eat in Room Child & .619 & 2.119 & 2.876 & 96 & $.005^{* *}$ \\
\hline Eat in Room Father - Eat in Room Child & .742 & 3.050 & 2.346 & 92 & $.021 *$ \\
\hline Eating Pace Mother - Eating Pace Father & -.013 & .961 & -.116 & 79 & .908 \\
\hline Eating Pace Mother - Eating Pace Child & .042 & .780 & .523 & 95 & .602 \\
\hline Eating Pace Father - Eating Pace Child & .086 & .883 & .881 & 80 & .381 \\
\hline Second Helping Mother - Second Helping Father & .034 & 1.191 & .267 & 88 & .790 \\
\hline Second Helping Mother - Second Helping Child & -.135 & 1.139 & -1.165 & 95 & .247 \\
\hline Second Helping Father - Second Helping Child & -.091 & .768 & -1.111 & 87 & .270 \\
\hline
\end{tabular}

Note. $* p<.05 ; * * p<.01 ; 2$-tailed.

\section{Discussion}

Being overweight or obese affects not only the person's physical but his/her overall sense of wellbeing. The cost of obesity is innumerable, and societal concern centers on the link between obesity and increased health risks that translate into increased medical care and costs (Thorpe et al., 2004). Obesity in children (7-12 years of age) and adolescents (13-17 years of age) is a serious issue with many health and social consequences that continue into adulthood. A similar pattern in overweight was also observed. Findings of this study corroborate earlier findings that, overall, ethnicity is a significant factor in TV and computer usage by parents and children, with Blacks spending more time than Hispanics or Filipinos. There are similarities in mothers' and children's eating paces, suggesting that children tend to adopt mothers' behavior, especially in single-family homes. Parents can prevent or control childhood overweight by advocating for increased family physical activity and providing healthy foods. Parents play a major role in modeling healthy lifestyle behaviors, providing highquality foods at home, limiting television viewing time, and exercising social responsibility and accountability for the welfare of their children (Ludwig, 2007). Also, families in which parents are physically active increase the likelihood that their children will be in better physical shape. It is critical to understand that overweight and obesity could be influenced by multiple factors, such as genetic and environmental influences, including lifestyle, body image, and self-esteem, as well as socioeconomic status.

The school is a logical place to begin promoting a fitness intervention. A school-based intervention can effectively increase physical activity and cardiovascular fitness. However, finding time to participate in physical activity is an issue at any age, and adolescent years are no exception. Exposure to western media almost inevitably leads to the adoption of western standards of beauty and dietary influences. Transitions in diet, nutrition, and activity patterns might have fueled the obesity epidemic (Parizkova et al., 2007); however, models for understanding and managing the nutrition transition often do not consider cultural influences, pursuit of beauty, and eating styles (Hawks et al., 2004). Cultural influences contribute to the nutrition transition such as perceptions of attractiveness and resulting eating styles. This shift in eating styles from intuitive to social eating may be another contributing factor to the rising levels of BMI that characterizes the nutrition transition. As the nutrition transition progresses, eating styles change from an intuitive focus on hunger satisfaction to a broader interest in social associations of food and the gratification of pleasure from eating (Hawks et al., 2004). However, the choices that individuals make and the course of action they follow is said to be dependent upon their self-efficacy. 


\section{Implications}

Statistics point to the importance of raising public awareness of the increasing prevalence and consequences of overweight and obesity in children and adolescents, particularly among at-risk ethnic minority groups. School-aged and adolescents are present-oriented and tend to exist in the present in actions, thoughts, and goals. Adolescents' particular attention to body image should be capitalized to motivate them about maintaining optimal body weight. By raising awareness about childhood obesity, a better understanding can be obtained to develop better treatment modalities. Given the significant disparities in obesity prevalence, program planners should ensure that those populations with the greatest need are involved in developing effective strategies for their communities for they are the ones that benefit the most from these efforts.

Many studies have found that Asians generally have a higher percentage of body fat than Caucasians, as measured by the use of the BMI. However, the BMI as a measure of obesity may not be appropriate to classify obesity among Asian populations, because the relationship between body fat percentage and BMI is ethnic and population specific (Parizkova et al., 2007). This can be partially explained by body build differences such as differences in trunk-to-leg ratio and differences in slenderness. A re-evaluation of BMI cut off values is needed particularly for Asians.

The findings provide a database for nurses and other health care providers to raise public awareness of lifestyle behaviors (eating and physical activity practices) that predispose children and adults to overweight and obesity. It is critical to do anticipatory counseling on nutrition and physical activity for overweight prevention in every client encounter. The inclusion of the cultural component will help explain the complexity of the nutrition transition, and promote targeted health strategies, research, and theory development. It behooves health care professionals to actively involve individuals, families, and communities in recognizing obesity as a critical problem and develop culture-specific health educational materials and teaching strategies to affect healthier child care practices, while simultaneously promoting mothers' sense of empowerment and self-efficacy.

\section{Limitations}

The data were based solely on self-reports of a convenience sample of mothers located in one geographical region in Florida, and therefore, do not reflect nationwide family eating and physical activity practices. Also, the sample is by convenience and does not reflect the population of Florida or the nation.

\section{Recommendations}

There is a need to replicate globally the study to establish the generalizability of the findings in a wider range of community settings and vulnerable population groups. Incorporation of planned physical activity, such as dance and healthier eating practices in lifestyle modification may prove to be cost-effective. Community-based agencies such as the school, neighborhood/community centers, and church need to work together to develop realistic and cohesive overweight and obesity prevention programs. Researchers must take the leadership in promoting theory development and research on obesity, while advanced nurse practitioners must take the initiative to implement targeted health strategies highlighting evidence-based practice. The BMI as a measure of obesity for Asians needs to be validated as indicated above. Development of more effective strategies for minority clients who may be dealing with multifaceted issues calls for understanding the factors that influence food choices and attitudes, as well as physical activity practices, including the unique role of culture and the limitations of modern life.

\section{Acknowledgment}

The author wishes to convey sincere thanks to data collectors, participating mothers, and collaborating clinical agencies.

\section{References}

Afable-Munsuz, A., Ponce, N. A., Rodriguez, M., \& PerezStable, E. J. (2010). Immigrant generation and physical activity among Mexican, Chinese \& Filipino adults in the U.S. Social Science Medicine, 70, 1997-2005. doi:10.1016/j.socscimed.2010. 02.026

Ammouri, A. A., Kaur, H., Neuberger, G. B., Gajewski, B., \& Choi, W. S. (2007). Correlates of exercise participation in adolescents. Public Health Nursing, 24, 111-120. doi:10.1111/j.1525-1446.2007. 00615.x

Booth, M. L., Wilkenfeld, R. L., Pagnini, D. L., Booth, S. L., \& King, L. A. (2008). Perceptions of adolescents on overweight and obesity: The Weight of Opinion Study. Journal of Pediatrics and Child Health, 44, 248-252. doi:10.1111/j.1440-1754.2007. 01267.x

Brooks, M. V., Leake, A., Parsons, C., \& Pham, V. (2012). A review of the literature: Evaluating dietary intake of Filipino Americans at risk for type 2 diabetes. Nursing Forum, 47, 27-33. doi:10.1111/ j.1744-6198.2011.00226.x

Butte, N. F., Puyau, M. R., Vohra, F. A., Adolph, A. L., Mehta, N. R., \& Zakeri, I. (2007). Body size, body composition, and metabolic profile explain higher 
energy expenditure in overweight children. The Journal of Nutrition, 137, 2660-2667.

Campbell, K. J., Crawford, D. A., Salmon, J., Carver, A., Garnett, S. P., \& Baur, L. A. (2007). Associations between the home food environment and obesitypromoting eating behaviors in adolescence. Obesity, 15, 719-730. doi:10.1038/oby.2007.553

Colchero, M. A., \& Bishai, D. (2008). Effect of neighborhood exposures on changes in weight among women in Cebu, Philippines. American Journal of Epidemiology, 167, 615-623. doi:10.1093/ aje/kwm340

Dammann, K. W., \& Smith, C. J. (2009). Factors affecting low-income women's food choices and the perceived impact of dietary intake and socioeconomic status on their health and weight. Journal of Nutrition Education and Behavior, 41, 242-53. doi:10.1016/j.jneb.2008.07.003

Davies, H. D., \& Fitzgerald, H. E. (2008). Obesity in childhood and adolescence (Vol. 1 \& 2). Westport, CT: Praeger Press.

Dhoble, A., Patel, K., \& Odoms-Young, A. (2007). Familial and behavioral determinants of obesity in Black children, and preventive strategies. The Internet Journal of Health, 7(2).

Dunphy, L. M., Brown-Winland, J. E., Porter, B. O., \& Thomas, D. J. (2015). Primary care: The art and science of advanced practice nursing (4th ed.). Philadelphia, PA: F.A. Davis Company.

Fitzgerald, H. E., \& Mousouli, V. (Eds.) (2008). Obesity in childhood and adolescence: Development and prevention (Vol. 2). Westport, CT: Praeger Press.

Flegal K. M, Carroll M. D, Kit B. K, \& Ogden C. L. (2012). Prevalence of obesity and trends in the distribution of body mass index among US adults, 1999-2010. Journal of the American Medical Association, 307, 491-97. doi:10.1001/jama.2012.39

Golan, M., \& Weizman, A. (1998). Reliability and validity of the Family Eating and Activity Habits Questionnaire. European Journal of Clinical Nutrition, 52, 771-777. doi:10.1038/sj.ejen.1600647

Hawaii Department of Health. (2011). Hawaii Behavioral Risk Factor Surveillance System. Retrieved from http://health.hawaii.gov/brfss/

Hawks, S. R., Merrill, R. M., Madanat, H. N., Miyagawa, T., Suwanteerangkul, J., Guarin, C., \& Shaofang, C. (2004). Intuitive eating and the nutrition transition in Asia. Asia Pacific Journal of Clinical Nutrition, 13, 194-203.

Huang, T. T., Ball, G. D., \& Franks, P. W. (2007). Metabolic syndrome in youth: Current issues and challenges. Applied Physiology, Nutrition, and Metabolism, 32, 13-22. doi:10.1139/h06-094

Hudson, C. E. (2008). An integrative review of obesity prevention in African American children. Issues in Comprehensive Pediatric Nursing, 31, 147-170. doi:10.1080/01460860802475168

Hughes, S. O., Anderson, C. B., Power, T. G., Micheli, N., Jaramillo, S. M., \& Nicklas, T. A. (2006). Measuring feeding in low-income African-American and Hispanic parents. Appetite, 46, 215-23. doi:10.1016/j.appet.2006.01.002

Javier, J. R., Huffman, L. C., \& Mendoza, F. S. (2007). Filipino child health in the United States: Do health and health care disparities exist? Preventing Chronic Disease, 4, A36.

Kelles, A., \& Adair, L. (2009). Offspring consume a more obesogenic diet than mothers in response to changing socioeconomic status and urbanization in Cebu, Philippines. International Journal of $\mathrm{Be}$ havioral Nutrition and Physical Activity, 6, 47-58. doi:10.1186/1479-5868-6-47

Kim, H. S., Park, S. Y., Grandinetti, A., Holck, P. S., \& Waslien, C. (2008). Major dietary patterns, ethnicity, and prevalence of type 2 diabetes in rural Hawaii. Nutrition, 24, 1065-1072. doi:10.1016/ j.nut.2008.05.008

Lob-Corzilius, T. (2007). Overweight and obesity in childhood--a special challenge for public health. International Journal of Hygiene and Environmental Health, 210, 585-589. doi:10.1016/j.ijheh.2007. 07.019

Ludwig, D. S. (2007). Childhood obesity -the shape of things to come. The New England Journal of Medicine, 357, 2325-2327. doi:10.1056/NEJMp0706538

Pan, L., Galuska, D. A., Sherry, B., Hunter, A. S., Rutledge, G. E., Dietz, W. H., \& Balluz, L. S. (2009). Differences in prevalence of obesity among Black, White, and Hispanic adults -United States, 20062008. Morbidity and Mortality Weekly Report, 58, 740-744.

Parizkova, J., Chun, M., Chia, M., \& Yang, J. (2007). An international perspective on obesity, health, and physical activity: current trends and challenges in China and Asia. Journal of Exercise Science \& Fitness, 5, 7-23.

Schmitz K. H., Lytle, L. A., Phillips, G. A., Murray, D. M., Birnbaum, A.S., \& Kubik, M. Y. (2002). Psychosocial correlates of physical activity and sedentary leisure habits in young adolescents: the Teens Eating for Energy and Nutrition at School study. Preventive Medicine, 202, 266-278. doi:10.1006/ pmed.2001.0982

Schneider, M., Dunton, G. F., Bassin, S., Graham, D. J., Eliakim, A. F., \& Cooper, D. M. (2007). Impact of a school-based physical activity intervention on fitness and bone in sedentary adolescent females. Journal of Physical Activity and Health, 4, 17-29. doi:10.1123/jpah.4.1.17

Sealy, Y. M. (2010). Parents' food choices: Obesity among minority parents and children. Journal of Community Health Nursing, 27, 1-11. doi:10.1080/ 07370010903466072

Thorpe, K. E., Florence, C. S., Howard, D. H., \& Joski, P. (2004). The impact of obesity on rising medical spending. Obesity Reviews, 12, 50-61.

Unger, J. B., Reynolds, K., Shakib, S., Spruijt-Metz, D., Sun, P., \& Johnson, C. A. (2004). Acculturation, physical activity, and fast-food consumption among Asian-American and Hispanic adolescents. Journal of Community Health, 29, 467-481. doi:10.1007/s10900-004-3395-3

Vieweg, V. R., Johnston, C. H., Lanier, J. O., Fernandez, A., \& Pandurangi, A. K. (2007). Correlation between high risk obesity groups and low socioeconomic status in school children. Southern Medical Journal, 100, 8-13. doi:10.1097/01.smj.0000253479. 03665.6f 
Wang, Y., \& Beydoun. M. A. (2007). The obesity epidemic in the United States--gender, age, socioeconomic, racial/ethnic, and geographic characteristics: A systematic review and meta-regression analysis. Epidemiologic Reviews, 29, 6-28. doi:10.1093/ epirev/mxm007
Young-Hyman, D., Schlundt, D. G., Herman-Wenderoth, L., \& Bozylinski, K. (2003). Obesity, appearance, and psychosocial adaptation in young African American children. Journal of Pediatric Psychology, 28, 463-472. doi:10.1093/jpepsy/jsg037 